
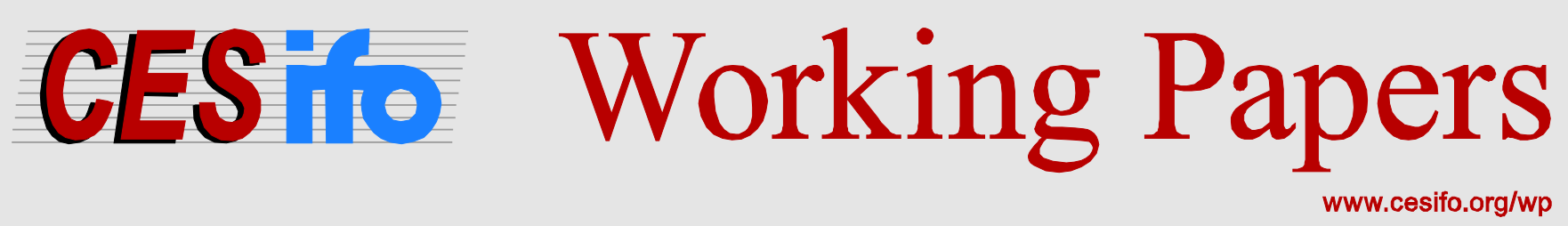

\title{
Emission Permits and Public Pollution Abatement: Can Decentralized Environmental Policies be Efficient?
}

\author{
Nikos Tsakiris \\ Panos Hatzipanayotou \\ Michael S. Michael
}

\begin{abstract}
CESIFO WORKING PAPER NO. 5278
CATEGORY 9: RESOURCE AND ENVIRONMENT ECONOMICS

MARCH 2015
\end{abstract}

An electronic version of the paper may be downloaded

- from the SSRN website:

- from the RePEc website:

- from the CESifo website:

wWw.SSRN.com

Www.RePEc.org

www.CESifo-group.org/wp 


\title{
Emission Permits and Public Pollution Abatement: Can Decentralized Environmental Policies be Efficient?
}

\begin{abstract}
We build a two regions general equilibrium model with cross-border pollution and either international or only inter-regional capital mobility. To control pollution each region uses public pollution abatement and issues either intra-regionally or inter-regionally tradable emission permits. We analyze the non-cooperative (decentralized) and cooperative (centralized) equilibrium level of emission permits and we examine when and how cross-border pollution and the type of capital mobility affect these equilibrium policies. We provide the welfare ranking of the policies in the various cases and we investigate under what conditions the decentralized and centralized equilibrium policies are equally efficient.
\end{abstract}

JEL-Code: F180, F210, H210.

Keywords: cross-border pollution, tradable emission permits, international capital mobility, public pollution abatement.

\author{
Nikos Tsakiris \\ Department of Economics \\ University of Ioannina \\ P.O. Box 1186 \\ Greece - 45110 Ioannina \\ ntsak@cc.uoi.gr
}

\author{
Panos Hatzipanayotou \\ Department of International and European \\ Economics Studies / Athens University of \\ Economics and Business \\ 76, Patission str. \\ Greece - Athens 10434 \\ hatzip@aueb.gr
}

\author{
Michael S. Michael \\ Department of Economics \\ University of Cyprus \\ P.O. Box 20537 \\ Cyprus - Nicosia, CY 1678 \\ m.s.michael@ucy.ac.cy
}

March 2015

The authors graciously acknowledge the constructive comments and suggestions by $\mathrm{H}$. Dellas, C. Dienes, C. Kotsogiannis, A. Philippopoulos, G. Economides, participants in the 70th Annual Congress of IIPF, in Lugano, Switzerland, and in the "Workshop on Public Sector Reform", Athens, Greece. Funding for this research project was provided by the European Social Fund (ESF) and the Greek NSRF-Research Funding Program: THALIS. The usual disclaimer applies. 


\section{Introduction}

A dominant current policy debate is that in the presence of cross-border pollution, such as greenhouse gas emissions, non-cooperative policies lead to inefficient outcomes. These concerns are amplified by the failure of the Copenhagen summit to achieve universal participation in a worldwide agreement for coordinating climate policies. Related to this, more often than not, countries are entangled into a "race to the bottom" in environmental policies due to increased competitive pressures resulting from wider and deeper globalization in commodity and factor markets. In light of the above, the following question arises: Can decentralized environmental policymaking lead to efficient outcomes in a globalized world?

Recently, Ogawa and Wildasin (2009), here on (OW), develop a model with many small open economies (jurisdictions) where capital is mobile between them, there is transboundary pollution, and a public consumption good. They show that governments acting non-cooperatively, set efficiently lump-sum taxes to finance the provision of the public good, and capital taxes to control for the environmental damage. That is, the decentralized policymaking coincides with the centralized one, leading to an efficient outcome. Their result holds regardless of the degree of cross-border pollution, thus extending the Oates and Schwab (1988) result where they considered only local pollution. ${ }^{1}$ Eichner and Runkel (2012), hereon (ER), confirm the (OW) result in a two-period model of capital adjustments when the elasticity of supply of capital with respect to the interest rate is zero, i.e., fixed intertemporal supply of capital. But, when the aforementioned supply elasticity is positive, then the (OW) result breaks down. Recently, Fell and Kaffine (2014) in a multi-jurisdictions, capital mobility and inter-jurisdictional pollution model introduce, first, "capital retirement", i.e., the possibility that the overall inter-jurisdictional capital stock is not fully allocated among them, thus leading to variable level of aggregate environmental damage, and second, a costly abatement activity. They show that the decentralized policy outcome generally differs from the solution of a centralized planner's social welfare-maximizing problem. ${ }^{2}$

\footnotetext{
${ }^{1}$ In a seminal contribution, Oates and Schwab (1988), (OS), in the context of small open-economy multijurisdictions, international capital mobility and local pollution, show that the decentralized setting of environmental standards can be consistent with first-best efficiency criterion, when each region sets optimally, i.e., equal to zero, capital taxes. Petchey (2014) extends this result by considering large open-economy jurisdictions, which can affect the net return to capital. In this framework, environmental standards can again be set optimally, i.e., consistent with first-best efficiency criterion, requiring, however, a non-zero capital tax.

${ }^{2}$ Keen and Kotsogiannis (2014) and Kotsogiannis and Woodland (2013), among others, examine the role of trade policy instruments, e.g., trade taxes, on globally efficient carbon taxes either from a non-cooperative or cooperative perspective (i.e., when international transfers are available or not). Other studies such as, Copeland and Taylor (1995, 2005), Helm (2003), and Antoniou et al. (2014), consider whether the non-cooperative issuance of internationally vs. nationally traded emission permits can lead to superior welfare outcomes in the
} 
Our paper contributes to this small but growing literature which examines the efficiency of decentralized vs. centralized policymaking in the presence of capital mobility and cross-border pollution, by raising the following considerations. First, hardly ever, one may think of capital taxes, or for that matter taxation of factors of production, as the instrument of controlling local or cross-border pollution as in (OW) and (ER). For example, nowadays, locally or internationally tradable emission permits constitute an important instrument for combating environmental degradation. The EU implements the so-called Emissions Trading Scheme (EU-ETS), the largest scheme of tradable permits worldwide, for controlling transnational $\mathrm{CO}_{2}$ emissions by large industrial sources, e.g., see Ellerman and Joskow (2008). In the US, inter-States emissions of Sulfur Dioxide $\left(\mathrm{SO}_{2}\right)$ are controlled by the Sulfur Allowance Trading Scheme (US-SATS). Because of the above reasons, in our analysis tradable emission permits, rather than capital taxes, is the instrument for controlling cross-border pollution. Second, in many OECD countries public pollution abatement activities constitute an important part of the environmental policy. ${ }^{3}$ These public sector pollution abatement activities can be viewed as an international public good since it also benefits other countries due to the transboundary nature of the pollution. Motivated by the above real world observations, we relate public sector activity to pollution abatement. This feature, absent in the above reviewed studies constitutes another important contribution of this study to the relevant literature. ${ }^{4}$

To address these issues, we consider a general equilibrium model comprising two regions, Home and Foreign. Capital is assumed to be either internationally mobile, or mobile only within the two regions. Production generated pollution is transmitted across borders. In controlling pollution, the two regions undertake two activities. First, they issue emissions permits which are either traded only locally among producers within the region, or are tradable by all producers in the two regions in an inter-regional emissions permits market.

presence of "rent-shifting", "terms of trade" and "emissions leakage" motives, due to imperfect competition and/or market power in world commodity markets.

${ }^{3}$ For example, a 2003 OECD report (Linster and Zegel 2007) states governments have designed policies of pollution abatement and control (PAC). PAC expenditures in OECD countries vary from 0.7 (Portugal 1994) to $2.6 \%$ (Austria 1998) of GDP per annum in the period 1990-2000. For most countries public expenditures account for about 40-60\% of total PAC. In the period 1990-2000 public PAC expenditures as a percentage of total PAC expenditures averaged 55 percent in Canada, Finland, France and Korea, 77 percent in Germany, 35 percent in Japan, and 40 percent in the US.

${ }^{4}(\mathrm{OW})$ and $(\mathrm{ER})$ consider the existence of a public "consumption" good totally unrelated to the environmental externality, whose presence, however, bears no impact on the results. For example,(OW) note " ....Public goods do not play a crucial role in the analysis and are included for the sake of generality and for comparison with environmental or other externalities ..”, p. 1208. 
Second, they use the proceeds from the sales of emission permits and lump-sum taxes to finance public pollution abatement. ${ }^{5}$

Within this framework we examine the non-cooperative (decentralized) and cooperative (centralized) equilibrium levels of tradable emission permits and identify the conditions under which they lead to the same outcome and are equally efficient. ${ }^{6}$ That is, for each region, we compare its Nash equilibrium level of tradable emission permits with its cooperative level of permits set to maximize the regions joint welfare. We find that when cross-border pollution is perfect and each region issues emission permits that are traded across the two regions then the centralized and decentralized policies lead to the same levels of emission permits and are equally efficient. This result holds regardless of the prevailing capital mobility regime. Moreover, we examine how the rate of cross border pollution and the capital mobility regime affect the cooperative and the non-cooperative equilibrium levels of emission permits.

\section{The Model}

We consider a general equilibrium model of two regions, Home and Foreign, which produce, consume and freely trade $(m)$ goods. In each region prices of goods are assumed fixed. ${ }^{7}$ Of all goods, the production of good 1 in both regions generates pollution emission. Production and consumption of all other goods are clean activities. There is a fixed capital endowment in each region, $\bar{K}$ and $\bar{K}^{*}$ for Home and Foreign respectively. ${ }^{8}$ Hereon, an $\left(^{*}\right)$ denotes Foreign's variables. For the purposes of our analysis, we consider two regimes of capital mobility. We call the first international capital mobility (ICM), and the second, inter-regional capital mobility (RCM). We refer to ICM as the case where capital is freely mobile between the two regions, as well as between the two regions and the "rest of the world". With RCM we refer to the case where although there is perfect mobility of capital between the two regions, the

\footnotetext{
${ }^{5}$ In direct contrast to the (OW) and (ER) models with a public consumption good, our analysis demonstrates that in the presence of cross-border pollution, public pollution abatement is important for the results.

${ }^{6}$ Despite the absence of a central authority in our model, we use the terms cooperative and centralized equilibrium interchangeably in the sense that when at equilibrium such an authority exists, then it would seek to maximize the regions joint welfare. Similarly, the terms Nash and decentralized equilibrium are interchangeably used in the sense that each region maximizes its welfare, taking the behavior of the other region as given.

${ }^{7}$ This assumption is widely used in the relevant literature, e.g., Oates and Schwab (1988), Ogawa and Wildasin (2009), Eichner and Runkel (2012).

${ }^{8}$ This assumption is in line with the multi-jurisdictions framework in Oates and Schwab (1988), and Ogawa and Wildasin (2009), where the total stock of capital is fixed. Eichner and Runkel (2012) and Fell and Kaffine (2014) consider the case of variable supply of capital.
} 
factor's mobility between the two regions and the rest of the world is totally restricted. ${ }^{9}$ All other factors of production are inter-regionally immobile and inelastically supplied; factor markets in both regions are perfectly competitive.

Production generated pollution is transmitted across regions, affecting negatively the utility of residents in both. With $0 \leq \theta \leq 1$ and $0 \leq \theta^{*} \leq 1$, respectively, we denote the rates of cross-border pollution transmitted from Foreign to Home and vice-versa. ${ }^{10}$ In controlling pollution, the two governments undertake two activities. First, they issue emission permits which are either intra-regionally tradable, i.e., traded only among producers within a region, or are inter-regionally tradable by all producers across both regions. Second, one of the traded goods, purchased at a constant price $P_{g}$, is used for public pollution abatement. ${ }^{11}$

The production side of the two regions is represented by the Gross Domestic Product (GDP) function. For Home, this function is depicted by $R\left(p^{\prime}, s_{i}, K\right)$.It captures the maximum value of production, at commodity price vector $p$, where a prime (')denotes a transposed vector; $s_{i}, i=n, t$, where $s_{n}\left(s_{t}\right)$ is the price of intra-regionally (inter-regionally) tradable emission permits. When permits are intra-regionally tradable, $s_{n}$ is determined in a region's permits market; when permits are inter-regionally tradable their price $s_{t}$ is determined in the inter-regional permits market. $K=\bar{K}-k$ is the amount of capital operating in Home, and $k>0(<0)$ is the amount Home's (Foreign and rest of the world's) capital operating in Foreign and the rest of the world (Home). The level of pollution $z$ is given by $z=-\partial R / \partial s_{i}=-R_{s_{i}}\left(s_{i}, K\right)$, and $R_{K}(=\partial R / \partial K)$ denotes the marginal revenue product of capital. Since $p$ is constant, the GDP function is written as $R\left(s_{i}, K\right)$. We assume that $R\left(s_{i}, K\right)$ is strictly concave in $K$, i.e., $R_{K K}<0$, implying that the marginal revenue product of capital is inversely related to changes in $K$, and strictly convex in $s_{i}$, i.e., $R_{s_{i} s_{i}}=-\left(\partial z / \partial s_{i}\right)>0$,

\footnotetext{
${ }^{9}$ Mobility of capital between the two regions, e.g., two regions in a federation such as New York and Pennsylvania is expected to be free. Capital mobility between the two regions and the rest of the world can be (i) perfectly free, (ii) totally restricted, or (iii) free but under some restrictions, e.g., due to institutional, legal or other constraints and impediments. Case (i) is what we call ICM and case (ii) is what we call RCM. Case (iii) is an in between case to (i) and (ii), see footnote 17 .

${ }^{10}$ We do not consider the possibility of cross-border pollution from these two regions into other regions or countries. This is a general specification of cross-border pollution with $\theta>0\left(\theta^{*}>0\right)$ being the fraction of pollution transmitted from Foreign (Home) to Home (Foreign).The assumption of perfectly transboundary pollution implies that $\theta=\theta^{*}=1$. The latter assumption is widely used in the relevant literature, e.g., see Vlassis (2013), Keen and Kotsogiannis (2014).

${ }^{11}$ The assumption that the price of the public pollution abatement good is constant is frequently used in the relevant literature.
} 
implying that an increase in $s_{i}$, due to tighter environmental policy, lowers demand for permits which in turn reduces production and the levels of production generated pollution. ${ }^{12}$ Similarly, Foreign's GDP function is defined as $R^{*}\left(s_{i}^{*}, K^{*}\right)$ where $K^{*}=\bar{K}^{*}-k^{*}$ is the supply of capital in Foreign, and $k^{*}>0(<0)$ is Foreign's (Home's and rest of world) capital operating in Home and the rest of the world (Foreign). Equivalently, $R_{K^{*}}^{*}\left(s_{i}^{*}, K^{*}\right)$ denotes the marginal revenue product of capital in Foreign and $z^{*}=-R_{s_{i}^{*}}^{*}\left(s_{i}^{*}, K^{*}\right)$ denotes the level of production generated pollution in Foreign, and it is also assumed that $R_{s_{i}^{*} s_{i}^{*}}^{*}>0$ and $R_{K^{*} K^{*}}^{*}<0$.

Overall pollution in Home $(r)$ and in Foreign $\left(r^{*}\right)$ consists of pollution locally generated and of pollution transmitted across borders from the other region, net of public pollution abatement in each region. For simplicity, we assume that in both regions one unit of production generates one unit of pollution and one unit of pollution abatement reduces pollution by one unit. Thus, we define: ${ }^{13}$

$$
r=z-g+\theta z^{*}-\theta g^{*}, r^{*}=z^{*}-g^{*}+\theta^{*} z-\theta^{*} g
$$

where $g$ and $g^{*}$ are the amounts of public pollution abatement in each region.

Each region comprises identical individuals whose utility is adversely affected by pollution. Home's demand side is represented by the minimum expenditure function, $E(r, u)$ capturing a representative individual's minimum expenditure on goods required to attain a given level of utility, $u$ at the constant commodity prices, omitted from the analysis, and overall pollution in the country, $r$. The partial derivatives $E_{u}(=\partial E / \partial u)$ and $E_{r}(=\partial E / \partial r)$, respectively, give the reciprocal of the marginal utility of income, and the household's marginal willingness to pay for reduction in pollution or marginal environmental damage.

\footnotetext{
${ }^{12}$ For detailed discussion of these and other related properties of the GDP function, see, e.g., Copeland (1994), Beghin et al. (1997) and Neary (2006). Copeland (2011) provides a comprehensive overview of all these theoretical issues. For example, in terms of our model, we can write the GDP function as $p_{1} q_{1}\left(K_{1}\right)+\sum_{j=2}^{m} q_{j}\left(K_{j}\right)=\left(1-s_{i}\right) q_{1}\left(K_{1}\right)+\sum_{j=2}^{m} q_{j}\left(K_{j}\right)=R\left(1, s_{i}, K\right), i=n, t$, where $p_{1}=\left(1-s_{i}\right)$ is the net producer price, and commodity prices are equal to one. By the envelope theorem we have that $\partial\left[(1-s) q_{1}\left(K_{1}\right)+\sum_{j=2}^{m} q_{j}\left(K_{j}\right)\right] / \partial s=-q_{1}\left(K_{1}\right)=\partial R(s, K) / \partial s=R_{s}(s, K)$. By our assumption that one unit of output creates one unit of pollution, $-R_{s}(s, K)=q_{1}=z$.

${ }^{13}$ Our specification implies that the two countries emit the same type of pollutant and that producers don't have access to the public abatement commodity. If for example the price of emission permits were higher than the cost of the public abatement commodity, producers would abate all pollution using this good, and would completely avoid, emissions permits, thus rendering environmental policies totally ineffective.
} 
$E_{r}$ is positive since pollution is a public bad. ${ }^{14}$ Similarly, Foreign's minimum expenditure function is given by $E^{*}\left(r^{*}, u^{*}\right)$.

Home (Foreign) issues emission permits $Z_{i}\left(Z_{i}^{*}\right)$ which are either traded locally within the region, or across the two regions. We refer to these two types of emission permits as intra-regionally and inter-regionally tradable emission permits. The cost of the public pollution abatement in Home (Foreign), i.e., $P_{g} g\left(P_{g} g^{*}\right)$, is financed through revenue from selling the emissions permits and lump-sum taxes, $T\left(T^{*}\right)$, and $P_{g}$ denotes the fixed price of the public abatement commodity $g\left(g^{*}\right) .{ }^{15}$ This formulation reflects the fact that in many countries proceeds from pollution taxes or other environmental policy instruments are earmarked for environmental clean-up. We assume that the governments maintain balanced budgets. That is

$$
P_{g} g=s_{i} Z_{i}+T, \quad \text { and } P_{g} g^{*}=s_{i}^{*} Z_{i}^{*}+T^{*} .
$$

In what follows, we examine the regions' Nash and cooperative equilibrium environmental policies, with intra-regionally and inter-regionally tradable emission permits, in the presence of cross-border pollution, public pollution abatement, and either ICM or RCM. We first consider the case of ICM.

\section{International capital mobility (ICM)}

In this case, capital is freely mobile between the two regions and between the two regions and the rest of the world. These capital flows, however, are assumed small relative to world capital flows without impact on the world rate of return to the factor $\rho$, which is considered

\footnotetext{
${ }^{14}$ For the properties of the expenditure function $E(r, u)$, its relationship to the direct utility and demand functions see the literature cited in footnote 12 .

${ }^{15}$ For tractability of the results, our formulation implies constant marginal abatement cost. Without loss of generality we could set $P_{g}=1$, but we refrain from this specification for clearer intuitive interpretation of the results. Analytically, our formulation is equivalent to assuming, as often done in the relevant literature, e.g., Ogawa and Wildasin (2009), that a consumer good, e.g., the numeraire, can be transformed one-to-one into a public good. One can think of the government choosing permits and lump-sum taxes with $g\left(g^{*}\right)$ being residually determined, or choosing permits and $g\left(g^{*}\right)$ with lump-sum taxes determined residually to balance the budget. The two formulations are equivalent, e.g., see Hadjiyiannis et al. (2009). We follow, as in (OW), the first specification. Moreover, as often done in the relevant literature, the existence of lump-sum taxes is to ensure the optimal provision of $g\left(g^{*}\right)$ in all cases. Thus, depending on whether or not permits revenues suffice to finance public abatement activity, $T$ and $T^{*}$ can be either negative, i.e., lump-sum subsidies, or positive, i.e., lump-sum taxes.
} 
fixed. ${ }^{16}$ Each region can be capital exporter or importer. Equilibrium in each region's capital market requires that the rate of return to capital equals its fixed world rate of return $(\rho){ }^{17}$

That is:

$$
R_{K}\left(s_{i}, K\right)=\rho \text { and } R_{K^{*}}^{*}\left(s_{i}^{*}, K^{*}\right)=\rho .
$$

Each region's income-expenditure identity requires that spending on goods equals income from production plus the net payments to their capital located abroad minus lump-sum taxes. That is,

$$
\begin{aligned}
& E(r, u)=R\left(K, s_{i}\right)+\rho k-T, \\
& E^{*}\left(r^{*}, u^{*}\right)=R^{*}\left(K^{*}, s_{i}^{*}\right)+\rho k^{*}-T^{*} .
\end{aligned}
$$

When a region is a capital exporter (importer) vis-à-vis the other region and the rest of the world, then, $k>(<) 0, k^{*}>(<) 0$. Irrespectively of the emission permits regime, the welfare effects of changes in lump-sum taxes are given as follows:

$$
\begin{aligned}
& P_{g} E_{u} \frac{d u}{d T}=\left(E_{r}-P_{g}\right), \quad P_{g} E_{u^{*}}^{*} \frac{d u^{*}}{d T}=\theta^{*} E_{r^{*}}^{*}, \\
& P_{g} E_{u^{*}}^{*} \frac{d u^{*}}{d T^{*}}=\left(E_{r^{*}}^{*}-P_{g}\right), \quad P_{g} E_{u} \frac{d u}{d T^{*}}=\theta E_{r} .
\end{aligned}
$$

When the two regions set lump-sum taxes non-cooperatively (Nash), the optimal provision of the public pollution abatement requires that $E_{r}=P_{g}=E_{r^{*}}^{*}$.

\subsection{Intra-regionally tradable emission permits}

First we consider the case where each region issues emission permits which are intraregionally tradable. Equilibrium in each region's permits market is achieved when the supply and demand for permits are equal. That is

\footnotetext{
${ }^{16}$ The case of ICM is in line with the "small region or country in world capital markets" assumption of the related economics literature. That is, first, since capital is internationally mobile, its rate of return must be equalized across the two regions and the rest of the world. Second, capital flows from one region to the other and to the rest of the world, are very small relative to world capital flows. As a result, such capital flows have a negligible effect on the capital stock and the rate of return to the factor in the other region and the rest of the world. Following the relevant literature these effects are assumed zero.

${ }^{17}$ If there are restrictions and impediments to capital mobility between the regions and the rest of the world, the equilibrium in the capital market can be written as $R_{K}\left(s_{i}, K\right)=R_{K^{*}}^{*}\left(s_{i}^{*}, K^{*}\right)=\rho+c$ where $c$ is the difference between the world and the regional rate of return to capital due to the impediments to capital mobility. If $c$ is constant, the analysis is identical to the case we call ICM.
} 


$$
\mathrm{Z}_{n}=z=-R_{s_{n}}\left(s_{n}, K\right) \text { and } \mathrm{Z}_{n}^{*}=z^{*}=-R_{s_{n}^{*}}^{*}\left(s_{n}^{*}, K^{*}\right) .
$$

The demand for pollution in Home (Foreign), i.e., $z\left(z^{*}\right)$, equals the supply of locally tradable emission permits, i.e., $Z_{n}\left(Z_{n}^{*}\right)$. Thus, overall pollution in each region is $r=Z_{n}-g+\theta Z_{n}^{*}-\theta g^{*}$ and $r^{*}=Z_{n}^{*}-g^{*}+\theta^{*} Z_{n}-\theta^{*} g$.

Equations (1)-(5) and (8) describe the economy of the two regions. Using these equations we get the welfare effects of an increase in the intra-regionally tradable emission permits as follows:

$$
\begin{gathered}
E_{u} \frac{d u}{d Z_{n}}=-E_{r} \frac{d r}{d Z_{n}}+R_{s_{n}} \frac{d s_{n}}{d Z_{n}} \Rightarrow P_{g} E_{u} \frac{d u}{d Z_{n}}=A_{Z_{n}}=\left(P_{g}-E_{r}\right) \tilde{R}_{s_{n} s_{n}}^{-1} Z_{n}+E_{r}\left(s_{n}-P_{g}\right), \\
P_{g} E_{u^{*}}^{*} \frac{d u^{*}}{d Z_{n}^{*}}=A_{Z_{n}^{*}}^{*}=\left(P_{g}-E_{r^{*}}^{*}\right) \tilde{R}_{s_{n}^{*} s_{n}}^{*-1} Z_{n}^{*}+E_{r^{*}}^{*}\left(s_{n}^{*}-P_{g}\right), \\
E_{u} \frac{d u}{d Z_{n}^{*}}=-E_{r} \frac{d r}{d Z_{n}^{*}}=\theta E_{r}\left[\left(s_{n}-P_{g}\right)-Z_{n}^{*} \tilde{R}_{s_{n}^{*} s_{n}^{*}}^{*-1}\right], P_{g} E_{u^{*}}^{*} \frac{d u^{*}}{d Z_{n}}=\theta^{*} E_{r^{*}}^{*}\left[\left(s_{n}-P_{g}\right)-Z_{n} \tilde{R}_{s_{n} s_{n}}^{-1}\right],
\end{gathered}
$$

where $\tilde{R}_{s_{n} s_{n}}=R_{s_{n} s_{n}}-R_{s_{n} K} R_{K K}^{-1} R_{K s_{n}}>0$ and $\tilde{R}_{s_{n}^{*} s_{n}^{*}}^{*}=R_{s_{n} s_{n}^{*}}^{*}-R_{s_{n}^{*} K^{*}}^{*} R_{K^{*} K^{*}}^{*-1} R_{K^{*} s_{n}^{*}}^{*}>0 .{ }^{18}$ Equations (9)(10) indicate that changes in a region's volume of emission permits affect its own welfare through changes in the total level of pollution and in the price of permits. Equations (11) show that changes in $Z_{n}^{*}\left(Z_{n}\right)$ affect Home's (Foreign's) welfare only when there is crossborder pollution between the two regions. Equations (A.1)-(A.3) in the Appendix provide details of these derivations.

\subsubsection{Nash versus cooperative equilibrium}

Setting $A_{Z_{n}}=0$ and $A_{Z_{n}^{*}}^{*}=0$ in equations (9)-(10), we obtain each region's best-response function. Solving them gives the Nash equilibrium levels of intra-regionally tradable emission permits $\left(Z_{n}^{N}, Z_{n}^{*_{N}}\right)$ with ICM, cross-border pollution and public pollution abatement. Since lump-sum taxes are Nash chosen by each region, then the two best-response functions

\footnotetext{
${ }^{18}$ We can write, $\tilde{R}_{s_{n} s_{n}}=-\left(d z / d s_{n}\right)=\left(\partial R_{s_{n}} / \partial s_{n}\right)+\left(\partial R_{s_{n}} / \partial K\right)\left(d K / d s_{n}\right)=R_{s_{n} s_{n}}-R_{s_{n} K} R_{K K}^{-1} R_{K s_{n}}>0$. That is, $\tilde{R}_{s_{n} s_{n}}$ captures the impact of changes in $s_{n}$ on $z$ directly and indirectly due to capital mobility. The signs of $\tilde{R}_{s_{n} s_{n}}$ follow straightforwardly from the properties of the GDP function. Similarly for $\tilde{R}_{s_{s} s_{n}^{*}}^{*}$.
} 
become $A_{Z_{n}}=E_{r}\left(s_{n}-P_{g}\right)=0$ and $A_{Z_{n}^{*}}^{*}=E_{r^{*}}^{*}\left(s_{n}^{*}-P_{g}\right)=0$. The Nash equilibrium levels of emission permits imply that $s_{n}=P_{g}=s_{n}^{*}$. It is evident that the rates of cross-border pollution do not affect the levels of $Z_{n}^{N}$ and $Z_{n}^{*_{N}}$.

When each region chooses the level of intra-regionally tradable emission permits cooperatively, so as to maximize the joint welfare, the cooperative equilibrium level of emission permits, $Z_{n}^{C}$, is determined by setting $E_{u}\left(d u / d Z_{n}\right)+E_{u^{*}}^{*}\left(d u^{*} / d Z_{n}\right)=0 . \quad Z_{n}^{* C}$ is determined by setting $E_{u}\left(d u / d Z_{n}^{*}\right)+E_{u^{*}}^{*}\left(d u^{*} / d Z_{n}^{*}\right)=0$.

To ascertain whether or not $Z_{n}^{N}$ is the same as $Z_{n}^{C}$, i.e., whether the non-cooperative choice of intra-regionally tradable emission permits is equally efficient as the cooperative one, we evaluate the joint welfare at the Nash equilibrium. That is, $E_{u}\left(d u / d Z_{n}\right)+E_{u^{*}}^{*}\left(d u^{*} / d Z_{n}\right)=E_{u^{*}}^{*}\left(d u^{*} / d Z_{n}\right)$, since at Nash equilibrium $E_{u}\left(d u / d Z_{n}\right)=0$. The Nash equilibrium level of emission permits by Home implies that $A_{Z_{n}}=0$, and since we assume that $E_{r}=P_{g}$, then we get that $s_{n}=P_{g}$, and equation (11) reduces to $P_{g} E_{u^{*}}^{*}\left(d u^{*} / d Z_{n}\right)=-\theta^{*} E_{r^{*}}^{*} Z_{n} \tilde{R}_{s_{n} s_{n}}^{-1}$. This expression indicates that $\left(d u^{*} / d Z_{n}\right)<0$ as long as pollution is transboundary, i.e., $\forall 0<\theta^{*} \leq 1$. It follows that the slope of the joint welfare function is negative at the Nash equilibrium. Therefore, the level of emission permits that maximizes the joint welfare is lower compared to that which emerges in the non-cooperative equilibrium, i.e., $Z_{n}^{N}>Z_{n}^{C}$. In this case, under ICM, the Nash (decentralized) equilibrium of intra-regionally tradable permits is less efficient than the cooperative (centralized) one. Intuitively, when $\theta^{*}>0$ and Home issues an additional permit, Home generated pollution exacerbates pollution in Foreign, affecting negatively its welfare. As a result of this negative externality, the Nash equilibrium level of emission permits and pollution are inefficiently high. If, however, $\theta^{*}=0$, then $\left(d u^{*} / d Z_{n}\right)=0$ and the slope of the joint welfare function at the Nash equilibrium is zero. In this case there is no pollution externality from Home to Foreign, and thus the cooperative and non-cooperative equilibrium levels of emission permits are the same and equally efficient.

The preceding analysis shows that the degree of cross-border pollution while it does not affect the Nash equilibrium level of intra-regionally tradable permits, it does affect the difference between $Z_{n}^{N}$ and $Z_{n}^{C}$. That is, higher $\theta^{*}$ increases, in absolute terms, the value of 
$\left(d u^{*} / d Z_{n}\right)$, and thus it increases the difference between $Z_{n}^{N}$ and $Z_{n}^{C}$. Similar analysis applies to Foreign. The following proposition summarizes the above results.

Proposition 1: Consider two regions with cross-border pollution and ICM. Each region issues intra-regionally tradable emission permits and uses public pollution abatement:

- At the Nash equilibrium, we obtain $E_{r}=E_{r^{*}}^{*}=P_{g}$ and $s_{n}=s_{n}^{*}=P_{g}$.

- The Nash equilibrium levels of $Z_{n}^{N}$ and $Z_{n}^{* N}$ are not affected by cross-border pollution.

- If $0<\theta^{*} \leq 1$, then (i) $Z_{n}^{C}<Z_{n}^{N}$, and (ii) $Z_{n}^{C}=Z_{n}^{N}$ if $\theta^{*}=0$.

- Given everything else the same, the difference between $Z_{n}^{C}$ and $Z_{n}^{N}$ increases as $\theta^{*}$ increases.

\subsection{Inter-regionally tradable emission permits}

Now the two regions issue inter-regionally tradable emission permits to control pollution, along with their public pollution abatement activity. Producers in Home (Foreign) can raise or lower the emission of production pollutants above or below the level of permits $Z_{t}\left(Z_{t}^{*}\right)$ by buying permits issued in Foreign (Home). Equilibrium in the inter-regional emission permits market requires that the sum of the emission permits issued must be equal to their demand across the two regions. That is

$$
Z_{t}+Z_{t}^{*}=z+z^{*}=-R_{s_{t}}\left(s_{t}, K\right)-R_{s_{t}}^{*}\left(s_{t}, K^{*}\right)
$$

where $s_{t}$ is the price for inter-regionally tradable emission permits, common for the two regions. Aggregate pollution in each region now is defined as $r=-R_{s_{t}}\left(s_{t}, K\right)-g-\theta\left(R_{s_{t}}^{*}\left(s_{t}, K^{*}\right)+g^{*}\right)$ and $r^{*}=-R_{s_{t}}^{*}\left(s_{t}, K^{*}\right)-g^{*}-\theta^{*}\left(R_{s_{t}}\left(s_{t}, K\right)+g\right)$.

The economy of the two regions is described by equations (1)-(5) and (12). Differentiating them gives the effects of changes in $Z_{t}$ and $Z_{t}^{*}$ on each region's welfare as follows:

$$
\begin{gathered}
P_{g} \tilde{H}_{s_{t} s_{t}} E_{u} \frac{d u}{d Z_{t}}=B_{Z_{t}}=\mathrm{E}_{r} \tilde{H}_{s_{t} s_{t}}\left(s_{t}-P_{g}\right)+E_{r} R_{s_{t}}^{*}+R_{s_{t}}\left(E_{r}-P_{g}\right)+\mathrm{E}_{r}(1-\theta)\left(Z_{t}^{*}+P_{g} \tilde{R}_{s_{t} s_{t}}^{*}\right), \\
P_{g} \tilde{H}_{s_{t} s_{t}} E_{u^{*}}^{*} \frac{d u^{*}}{d Z_{t}^{*}}=B_{Z_{t}^{*}}^{*}=E_{r^{*}}^{*} \tilde{H}_{s_{t} s_{t}}\left(s_{t}-P_{g}\right)+E_{r^{*}}^{*} R_{s_{t}}+R_{s_{t}}^{*}\left(E_{r^{*}}^{*}-P_{g}\right)+E_{r^{*}}^{*}\left(1-\theta^{*}\right)\left(Z_{t}+P_{g} \tilde{R}_{s_{t} s_{t}}\right),
\end{gathered}
$$


where $\tilde{H}_{s_{t} s_{t}}=\tilde{R}_{s_{t} s_{t}}+\tilde{R}_{s_{t} s_{t}}^{*}>0$. Details are given by equations (A.4)-(A.8) in the Appendix.

\subsubsection{Nash versus cooperative equilibrium}

Setting $\quad B_{Z_{t}}=0$ and $B_{Z_{t}^{*}}^{*}=0$ in equations (13)-(14), we get each region's best-response function. Solving them we obtain the Nash equilibrium levels of inter-regionally tradable emission permits $\left(Z_{t}^{N}, Z_{t}^{*_{N}}\right)$ with ICM, cross-border pollution and public pollution abatement. ${ }^{19}$ Regions choose the levels of inter-regionally tradable emission permits cooperatively, i.e., $Z_{t}^{C}$ and $Z_{t}^{* C}$, to maximize their joint welfare, by setting $E_{u}\left(d u / d Z_{t}\right)+E_{u^{*}}^{*}\left(d u^{*} / d Z_{t}\right)=0$ and $E_{u}\left(d u / d Z_{t}^{*}\right)+E_{u^{*}}^{*}\left(d u^{*} / d Z_{t}^{*}\right)=0$. To ascertain whether $Z_{t}^{N}$ is lower or higher than $Z_{t}^{C}$, we again evaluate the joint welfare function $E_{u}\left(d u / d Z_{t}\right)+E_{u^{*}}^{*}\left(d u^{*} / d Z_{t}\right)=E_{u^{*}}^{*}\left(d u^{*} / d Z_{t}\right)$ at the Nash equilibrium, since at Nash $E_{u}\left(d u / d Z_{t}\right)=0$. Differentiating equations (1)-(5) and (12) with respect to $Z_{t}$ yields:

$$
E_{u^{*}}^{*} \frac{d u^{*}}{d Z_{t}}=-E_{r^{*}}^{*} \frac{d r^{*}}{d Z_{t}}+R_{s_{t}}^{*} \frac{d s_{t}}{d Z_{t}}=-P_{g}^{-1} E_{r^{*}}^{*}\left(1-\theta^{*}\right) s_{t}+E_{u^{*}}^{*} \frac{d u^{*}}{d Z_{t}^{*}} .
$$

Details for this result are given by equations (A.4)-(A.8) in the Appendix.

The following results emerge from this latter expression at the Nash equilibrium where $\left(d u^{*} / d Z_{t}^{*}\right)=0$. First, $\left(d u^{*} / d Z_{t}\right)<0, \forall 0 \leq \theta^{*}<1$, which implies that at the Nash equilibrium, the slope of the joint welfare function is negative. Thus the cooperative choice of the number of $Z_{t}$ is lower than the one of the Nash equilibrium, i.e., $Z_{t}^{N}>Z_{t}^{C}$. When $\theta^{*}=1$ then $\left(d u^{*} / d Z_{t}\right)=0$. This is to say that evaluated at Nash equilibrium, the slope of the joint welfare function is zero. Thus, the centralized and decentralized equilibrium levels of emission permits are equal, i.e., $Z_{t}^{N}=Z_{t}^{C}$, and equally efficient. Intuitively, when Home issues more permits, affects Foreign's welfare through two channels. On the one hand, it inflicts a negative externality on Foreign's welfare due to higher cross-border pollution. On the other hand, a higher volume $Z_{t}$ lowers $s_{t}$, the price of inter-regionally tradable emission

\footnotetext{
${ }^{19}$ Differentiating the best response functions with respect to $\left(\theta, \theta^{*}\right)$, assuming that the third derivatives are zero, we can show that at Nash equilibrium where $E_{r}=E_{r^{*}}^{*}=P_{g}$, an increase in $\theta$ decreases $Z_{t}^{N}$, increases $Z_{t}^{* N}$ and decreases (does not affect) $Z_{t}^{N}+Z_{t}^{* N}$ if $\theta^{*}<1\left(\theta^{*}=1\right)$.
} 
permits, thus, it increases Foreign's demand for permits, production and income. This entails a positive externality of the higher $Z_{t}$ on Foreign's welfare. Faced with a higher $Z_{t}$, Foreign's best response is to lower its volume of permits $Z_{t}^{*}$. In particular, when $\theta^{*}=1$, its best response is to reduce its pollution permits by the same amount i.e., $d Z_{t}^{*}=-d Z_{t} \cdot{ }^{20}$ In this case total pollution in Foreign remains the same (see equations A.6). Since $d Z_{t}^{*}=-d Z_{t}$ the emission price is also unchanged. ${ }^{21}$ Therefore, when $\theta^{*}=1$ the increase in $Z_{t}$ does not affect Foreign's welfare and thus the Nash equilibrium is efficient. When $\theta^{*}<1$, and Home raises $Z_{t}$, Foreign's pollution increase is lower and its best response is to decrease $Z_{t}^{*}$ but by a smaller amount than the increase in $Z_{t}$ i.e., $\left|d Z_{t}^{*}\right|<\left|d Z_{t}\right|$ (see footnote 20). In this case, the increase in $Z_{t}$ increases foreign pollution even after taking into account Foreign's best response which calls for a reduction in $Z_{t}^{*}$ (negative externality). ${ }^{22}$ Since the total number of emission permits in the two regions increases, the price of emission permits decreases, output increases, creating a positive externality. The negative externality, however, outweighs the positive one and thus Foreign's welfare decreases. Thus, in this case the Nash equilibrium level of emission permits is inefficiently high. Finally, observing equation (15) we can infer the following. First, the previous results hold for any level of public pollution abatement. Second, given everything else the same, the smaller is the rate $\theta^{*}$, the greater is the disparity between $Z_{t}^{N}$ and $Z_{t}^{C}$. Proposition 2 summarizes the above results.

Proposition 2: Consider two regions with cross-border pollution and ICM. Each region uses inter-regionally tradable emission permits and public pollution abatement:

- If $\theta^{*}=1$, then $Z_{t}^{N}=Z_{t}^{C}$, but if $\theta^{*}<1$, then $Z_{t}^{N}>Z_{t}^{C}$.

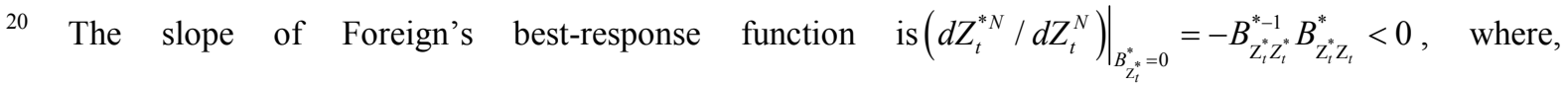
$B_{Z_{t} Z_{t}^{*}}^{*}=\left(1+\tilde{R}_{s_{t} s_{t}} \tilde{H}_{s_{t} s_{t}}^{-1}\right)>0$, and $B_{Z_{t}^{*} Z_{t}}^{*}=\left(\theta^{*}+\tilde{R}_{s_{t} s_{t}} \tilde{H}_{s_{t} s_{t}}^{-1}\right)>0$. The slope of the best-response function is negative implying that $\left(Z_{t}^{N}, Z_{t}^{* N}\right)$ are strategic substitutes. When $\theta^{*}=1$, then $\left(d Z_{t}^{* N} / d Z_{t}^{N}\right)_{B_{Z_{i}^{*}}^{*}=0}=-1$, and when $\theta^{*}<1$, then $\left|\left(d Z_{t}^{* N} / d Z_{t}^{N}\right)_{B_{Z_{t}^{*}}^{*}=0}\right|<1$.

${ }^{21}$ When $d Z_{t}^{*}=-d Z_{t}$, using the permits market equilibrium condition, equation (12), the emission price does not change since the stock of capital in each region remains unchanged. That is, $\left(d K^{*} / d Z_{t}^{*}\right)=\left(d K^{*} / d Z_{t}\right)$ and $\left(d K / d Z_{t}^{*}\right)=\left(d K / d Z_{t}\right)$ see equation (A.5).

${ }^{22}$ It can be shown that $\left(\partial r^{*} / \partial Z_{t}\right)+\left(\partial r^{*} / \partial Z_{t}^{*}\right)\left(d Z_{t}^{*} / d Z_{t}\right)$ is positive. See also equations (A.6) in Appendix. 
- Everything else the same, the difference between $Z_{t}^{N}$ and $Z_{t}^{C}$ decreases with a higher $\theta^{*}$.

\subsection{Intra-regional versus inter-regional tradable permits.}

The previous analysis shows that when lump-sum taxes are Nash chosen and pollution is only local, then the Nash and cooperative equilibrium levels of intra-regionally tradable emission permits are the same and thus equally efficient. In the presence of cross-border pollution, the Nash equilibrium level of intra-regionally tradable emission permits is higher than that of the cooperative equilibrium and it reaches its highest level with perfect cross-border pollution. Thus, when $\theta^{*}=1$ the Nash equilibrium level of intra-regionally tradable emission permits is the highest and this is the most inefficient equilibrium.

When permits are inter-regionally tradable and cross-border pollution is perfect, then the Nash and cooperative equilibrium levels of such emission permits are identical and thus the Nash equilibrium is efficient. When, however, the degree of cross-border pollution is zero, then the difference between the Nash and cooperative equilibrium levels of interregionally tradable emission permits is the largest, and thus the Nash level of emission permits is at their most inefficient level. Therefore, when the two regions do not cooperate, and cross-border pollution is zero, then issuing intra-regionally tradable emission permits is efficient while when cross-border pollution is perfect, then it is the most inefficient. The opposite holds in a regime of inter-regionally tradable emission permits. Thus, we can argue that when $\theta^{*}=\theta$ there is a critical value $\hat{\theta}$ for which if $0<\theta^{*}=\theta<\hat{\theta}$, it is less inefficient for both regions to issue intra-regionally tradable emission permits while if $1>\theta^{*}=\theta>\hat{\theta}$ it is less inefficient for both regions to issue inter-regionally tradable emission permits.

Corollary 1: Assume that both regions set public pollution abatement and tradable emission permits non-cooperatively, and that $\theta=\theta^{*}$. There is a critical value $\hat{\theta}$ for which if $0<\theta=\theta^{*}<\hat{\theta}$ then it is less inefficient for both regions to issue intra-regionally tradable permits. If $1>\theta=\theta^{*}>\hat{\theta}$, then it is less inefficient for both regions to issue inter-regionally tradable permits.

\section{Inter-regional capital mobility (RCM)}

As noted in the introduction, RCM is the case of free capital mobility between the two regions and of completely restricted mobility between the two regions and the rest of the 
world. Equilibrium in the inter-regional capital market requires that the rate of return to capital is endogenously determined and equalized across the two regions. ${ }^{23}$ That is:

$$
R_{K}\left(s_{i}, K\right)=R_{K^{*}}^{*}\left(s_{i}^{*}, K^{*}\right)
$$

Home, is designated as a capital-importer, and Foreign as a capital-exporter. Thus, for Home, $K=\bar{K}+k$, for Foreign, $K^{*}=\bar{K}^{*}-k$ and $d K=-d K^{*}=d k$. The income-expenditure identity for each region is given as:

$$
\begin{aligned}
& E(r, u)=R\left(K, s_{i}\right)-k R_{K}\left(K, s_{i}\right)-T, \\
& E^{*}\left(r^{*}, u^{*}\right)=R^{*}\left(K^{*}, s_{i}^{*}\right)+k R_{K}\left(K, s_{i}\right)-T^{*} .
\end{aligned}
$$

\subsection{Intra-regionally tradable emission permits}

We first examine the case where each region issues emission permits which are only intraregionally tradable. Equilibrium in each region's permits market is given by equations (8), and overall pollution in each region is again defined as $r=Z_{n}-g+\theta Z_{n}^{*}-\theta g^{*}$ and $r^{*}=Z_{n}^{*}-g^{*}+\theta^{*} Z_{n}-\theta^{*} g$. The two regions economy is described by equations (1), (2), (8), (16)-(18). Using these equations, we obtain for each region the welfare effects of changes in the levels of intra-regionally tradable emission permits as follows:

$$
\begin{aligned}
& P_{g} \Delta_{n} E_{u} \frac{d u}{d Z_{n}}=F_{Z_{n}}=- \Delta_{n} E_{r}\left(P_{g}-s_{n}\right)-Z_{n}\left(E_{r}-P_{g}\right) R_{s_{n}^{*} s_{n}^{*}}^{*}\left(R_{K K}+\tilde{R}_{K^{*} K^{*}}^{*}\right)+\theta E_{r} Z_{n}^{*} R_{K s_{n}} R_{s_{n}^{*} K^{*}}^{*} \\
&+k P_{g} R_{K s_{n}} R_{s_{n}^{*} s_{n}^{*}}^{*} \tilde{R}_{K^{*} K^{*}}^{*}, \\
& P_{g} \Delta_{n} E_{u^{*}}^{*} \frac{d u^{*}}{d Z_{n}^{*}}=F_{Z_{n}^{*}}^{*}=-\Delta_{n} E_{r^{*}}^{*}\left(P_{g}-s_{n}^{*}\right)-Z_{n}^{*}\left(E_{r^{*}}^{*}-P_{g}\right) R_{s_{n} s_{n}}\left(R_{K K}+\tilde{R}_{K^{*} K^{*}}^{*}\right)+\theta^{*} E_{r^{*}}^{*} Z_{n} R_{K s_{n}} R_{s_{n}^{*} K^{*}}^{*} \\
&-k P_{g} R_{K s_{n}} R_{s_{n}^{*} s_{n}^{*}}^{*} \tilde{R}_{K^{*} K^{*}}^{*},
\end{aligned}
$$

where $\Delta_{n}=R_{s_{n}^{*} s_{n}}^{*} \tilde{R}_{s_{n} s_{n}} R_{K K}+R_{s_{n} s_{n}} \tilde{R}_{s_{n} s_{n}^{*}}^{*} R_{K^{*} K^{*}}^{*}<0$ and $\tilde{R}_{K^{*} K^{*}}^{*}=R_{K^{*} K^{*}}^{*}-R_{K^{*} s_{n}^{*}}^{*} R_{s_{n} s_{n}^{*}}^{*-1} R_{s_{n}^{*} K^{*}}^{*}<0$. Details of these derivations are given by equations (A.9)-(A.14) in the Appendix. The comparison of equations (19)-(20) and (9)-(10) reveals the differences in the way that the presence of RCM

\footnotetext{
${ }^{23}$ Oates and Schwab (1988), and Ogawa and Wildasin (2009), while consider inter-regional mobility of capital and fixed total supply in the two regions, as we do in the case of RCM, they assume, contrary to our specification, exogenous net rate of return to the factor.
} 
and ICM alter the impact of changes in $Z_{n}$ and $Z_{n}^{*}$ on $u$ and $u^{*}$. These effects, absent in equations (9)-(10), are captured by the last two right-hand-side terms in equations (19)-(20).

\subsubsection{Nash versus cooperative equilibrium}

From equations (19)-(20), solving the regions' best-response functions $F_{Z_{n}}=0$ and $F_{Z_{n}^{*}}^{*}=0$, we obtain the Nash equilibrium levels of intra-regionally tradable emission permits $\left(Z_{n}^{N}, Z_{n}^{*_{N}}\right)$ with RCM, cross-border pollution and public pollution abatement. Equations (19)-(20), contrary to equations (9)-(10), indicate that with RCM, the Nash equilibrium levels of intraregionally tradable emission permits depend on the rates of cross-border pollution $\left(\theta, \theta^{*}\right)$.

When each region chooses the level of emission permits to maximize the joint welfare, Home chooses $Z_{n}$ so that $E_{u}\left(d u / d Z_{n}\right)+E_{u^{*}}^{*}\left(d u^{*} / d Z_{n}\right)=0$. Following the same methodology as before, we evaluate $\left(d u^{*} / d Z_{n}\right)$ at the Nash equilibrium where $\left(d u / d Z_{n}\right)=0$ and $\left(d u^{*} / d Z_{n}^{*}\right)=0$. In order to facilitate the analysis we assume that the two regions are symmetric, so that $k=0 .{ }^{24}$ Note that $E_{r}=P_{g}=E_{r^{*}}^{*}$. Using that $\left(d u / d Z_{n}\right)=0$ in the Nash equilibrium, we obtain: ${ }^{25}$

$$
E_{u^{*}}^{*} \frac{d u^{*}}{d Z_{n}}=-E_{r^{*}}^{*} \frac{d r^{*}}{d Z_{n}}+R_{s_{n}}^{*} \frac{d s_{n}^{*}}{d Z_{n}}=-\left(\Delta_{n} P_{g}\right)^{-1} \theta^{*} E_{r^{*}}^{*}\left[\theta Z_{n}^{* N} R_{K s_{n}} R_{s_{n}^{*} K^{*}}^{*}+Z_{n}^{N} R_{s_{n} s_{n}^{*}}^{*}\left(R_{K K}+\tilde{R}_{K^{*} K^{*}}^{*}\right)\right] .
$$

Equation (21) indicates that even in the case of symmetric regions, evaluating $\left(d u^{*} / d Z_{n}\right)$ at the Nash equilibrium we get an ambiguous sign. That is, in the presence of $\mathrm{RCM}$, the non-cooperative equilibrium level of intra-regionally tradable emission permits can be above or below the level given in the cooperative equilibrium. In what follows we consider some special cases. First, if $\theta^{*}=0$ then evaluated at the Nash equilibrium, $\left(d u^{*} / d Z_{n}\right)=0$, thus $Z_{n}^{N}=Z_{n}^{C}$. Intuitively, the increase in $Z_{n}$ reduces the price of the emission permits $\left(s_{n}^{*}\right)$ in Foreign (see A.10) and increases Foreign's GDP, thus raises its

\footnotetext{
${ }^{24}$ By symmetry of the two regions we mean that they have identical factor endowments and production technologies. The same results could be obtained if we assume, as in (OW), that the return to capital is fixed. In this case the last term in equations (19) and (20) is absent.

${ }^{25}$ Since $E_{r}=P_{g}=E_{r^{*}}^{*}$, when $k=0$, equation (19) yields $\Delta_{n}\left(P_{g}-s_{n}\right)=\theta Z_{n}^{*} R_{K s_{n}} R_{s_{n} K^{*}}^{*}$. Substituting this result into equation (A.14), we obtain equation (21).
} 
welfare, i.e., a positive externality. ${ }^{26}$ However, although $\theta^{*}=0$, the increase in $Z_{n}$ increases net pollution in Foreign since $r^{*}=Z_{n}^{*}-g^{*}$ and since the reduction in the price of emission permits reduces emission revenue and public pollution abatement, i.e., a negative externality. These two effects, however, cancel each other and so Foreign's welfare remains unaffected. Thus, when $\theta^{*}=0$ the Nash equilibrium is efficient. Second, if $0<\theta^{*} \leq 1$ and $\theta=0$ or very small, then evaluated at the Nash equilibrium, $\left(d u^{*} / d Z_{n}\right)<0$, thus $Z_{n}^{N}>Z_{n}^{C}$. Intuitively, when $0<\theta^{*} \leq 1$, the increase in $Z_{n}$ increases pollution in Foreign by more relative to when $\theta^{*}=0$. This cross-border pollution effect enhances the negative pollution externality that exists when $\theta^{*}=0$. Now, this overall negative pollution externality outweighs the positive one. In this case the Nash equilibrium level of emission permits is inefficiently high.

Finally, consider, the case where $\theta$ is very large and $\theta^{*}$ is very small. In this case, the Nash equilibrium level of Foreign's tradable permits $Z_{n}^{* N}$ is high while that of Home's $Z_{n}^{N}$ is low. ${ }^{27}$ Then, according to equation (21), it is possible for $\left(d u^{*} / d Z_{n}\right)$ to be positive when evaluated at the Nash equilibrium, implying that $Z_{n}^{N}<Z_{n}^{C}$. Intuitively, when $\theta$ is very large and $\theta^{*}$ is very small, $Z_{n}^{* N}$ is large while $Z_{n}^{N}$ is small. Since $\theta^{*}$ is very small, the increase in foreign pollution is small, (small negative externality) and it could be outweighed by the positive externality created from the reduction in foreign emission price. In this case the Nash equilibrium level of emission permits could be inefficiently low.

Proposition 3: Consider two regions with cross-border pollution and RCM. Each region uses intra-regionally tradable emission permits and public pollution abatement. Assume that the two regions are symmetric so that $k=0$ :

- At the Nash equilibrium, for positive $\theta$, we obtain $s_{n}>P_{g}$.

- If $\theta^{*}=0$ then $Z_{n}^{N}=Z_{n}^{C}$. If $0<\theta, \theta^{*} \leq 1$, then $Z_{n}^{N}$ can be lower or higher than $Z_{n}^{C}$.

- Given everything else constant, the difference between $Z_{n}^{C}$ and $Z_{n}^{N}$ increases with an increase in $\theta^{*}$.

\footnotetext{
${ }^{26}$ Foreign's GDP function can be written as $p_{1}^{*} q_{1}^{*}\left(K_{1}^{*}\right)+\sum_{j=2}^{m} q_{j}^{*}\left(K_{j}^{*}\right)=\left(1-s_{n}^{*}\right) q_{1}^{*}\left(K_{1}^{*}\right)+\sum_{j=2}^{m} q_{j}^{*}\left(K_{j}^{*}\right)=R^{*}\left(1, s_{n}^{*}, K^{*}\right)$, where $p_{1}^{*}=\left(1-s_{n}^{*}\right)$. Then, a decrease in $s_{n}^{*}$ increases Foreign's GDP, i.e., $\partial R^{*} / \partial s_{n}^{*}=R_{s_{n}^{*}}^{*}=-q_{1}^{*}$.

${ }^{27}$ Equations (A.16) in the Appendix show that an increase in $\theta\left(\theta^{*}\right)$ decreases (increases) $Z_{n}^{N}$, increases (decreases) $Z_{n}^{* N}$. Thus, when $\theta$ is very large and $\theta^{*}$ is very small, given everything else the same, we expect that $Z_{n}^{* N}$ is large while $Z_{n}^{N}$ is small.
} 


\subsection{Inter-regionally tradable emission permits}

Now the two regions control pollution via inter-regionally tradable emission permits. As previously shown, aggregate pollution in the two regions is defined again as $r=-R_{s_{t}}\left(s_{t}, K\right)-g-\theta\left(R_{s_{t}}^{*}\left(s_{t}, K^{*}\right)+g^{*}\right)$ and $r^{*}=-R_{s_{t}}^{*}\left(s_{t}, K^{*}\right)-g^{*}-\theta^{*}\left(R_{s_{t}}\left(s_{t}, K\right)+g\right)$.

Differentiating equations (1), (2), (12) and (16)-(18), gives the effects of changes in $Z_{t}$ and $Z_{t}^{*}$ on each region's welfare as follows:

$$
\begin{aligned}
& P_{g} \bar{H}_{s_{t} s_{t}} E_{u} \frac{d u}{d Z_{t}}=G_{Z_{t}}=E_{r} \bar{H}_{s_{t} s_{t}}\left(s_{t}-P_{g}\right)+R_{s_{t}}\left(E_{r}-P_{g}\right) \\
&+E_{r}\left[R_{s_{t}}^{*}+(1-\theta)\left(Z_{t}^{*}+P_{g} R_{s_{t} s_{t}}^{*}+P_{g} R_{K^{*} s_{t}}^{*} H_{K K}^{-1} H_{K s_{t}}\right)\right]+k P_{g} H_{K K}^{-1}\left(R_{K K} R_{K^{*} s_{t}}^{*}+R_{K s_{t}} R_{K^{*} K^{*}}^{*}\right), \\
& P_{g} \bar{H}_{s_{t} s_{t}} E_{u^{*}}^{*} \frac{d u^{*}}{d Z_{t}^{*}}=G_{Z_{t}^{*}}^{*}=E_{r^{*}}^{*} \bar{H}_{s_{t} s_{t}}\left(s_{t}-P_{g}\right)+R_{s_{t}}^{*}\left(E_{r^{*}}^{*}-P_{g}\right) \\
&+E_{r^{*}}^{*}\left[R_{s_{t}}+\left(1-\theta^{*}\right)\left(Z_{t}+P_{g} R_{s_{t} s_{t}}-P_{g} R_{s_{t} K} H_{K K}^{-1} H_{K s_{t}}\right)\right]-k P_{g} H_{K K}^{-1}\left(R_{K K} R_{K^{*} s_{t}}^{*}+R_{K s_{t}} R_{K^{*} K^{*}}^{*}\right),
\end{aligned}
$$

where $\bar{H}_{s_{t} s_{t}}=H_{s_{t} s_{t}}-H_{s_{t} K} H_{K K}^{-1} H_{K s_{t}}>0, \quad H_{K K}=R_{K K}+R_{K^{*} K^{*}}^{*}<0 \quad$ and $\quad H_{K s_{t}}=R_{K s_{t}}-R_{K^{*} s_{t}}^{*}$. Equations (A.17)-(A.19) in the Appendix provide details for these results.

\subsubsection{Nash versus cooperative equilibrium}

Setting $G_{Z_{t}}=0$ and $G_{Z_{t}^{*}}^{*}=0$ we solve for the Nash equilibrium levels of inter-regionally tradable emission permits $\left(Z_{t}^{N}, Z_{t}^{* N}\right)$, with RCM, cross-border pollution and public pollution abatement. When each region chooses the level of emission permits to maximize the joint welfare, following the same procedure as before, we need to evaluate $\left(d u^{*} / d Z\right)$ at the Nash equilibrium. Using equations (1), (2), (12) and (16)-(18) gives the effect of changes in $Z_{t}$ on Foreign's welfare as follows:

$$
P_{g} E_{u^{*}}^{*} \frac{d u^{*}}{d Z_{t}}=-E_{r^{*}}^{*}\left(1-\theta^{*}\right) s_{t}+P_{g} E_{u^{*}}^{*} \frac{d u^{*}}{d Z_{t}^{*}}
$$

For details see equations (A.17)-(A.20) in the Appendix. At the Nash equilibrium where $\left(d u^{*} / d Z_{t}^{*}\right)=0$, equation (24) shows that if $0 \leq \theta^{*}<1$ then $\left(d u^{*} / d Z_{t}\right)$ is negative. Thus, at the 
Nash equilibrium, the slope of the joint welfare function is negative, implying that $Z_{t}^{C}<Z_{t}^{N}$. If, however, $\theta^{*}=1$, then the slope of the joint welfare function at the Nash equilibrium is zero, implying that the cooperative and the Nash equilibrium level of emission permits are the same. Thus, when $\theta^{*}=1$ then the Nash equilibrium is identical to the cooperative equilibrium and equally efficient. The intuitive explanation of this case is similar to that of section 3.2. Note that this result is valid for any level of public pollution abatement and without assuming symmetry of the two regions. Using equations (24) we state the following proposition.

Proposition 4: Consider two regions with cross-border pollution and RCM. Each region uses inter-regionally tradable emission permits and public pollution abatement.

- If $\theta^{*}=1$, then $Z_{t}^{N}=Z_{t}^{C}$, but if $\theta^{*}<1$, then $Z_{t}^{N}>Z_{t}^{C}$.

- Given everything else the same, a higher $\theta^{*}$ decreases the difference between $Z_{t}^{N}$ and $Z_{t}^{C}$

Comparing equations (15) and (24) reveals that the two equations are identical. Based on them we state the following corollary.

Corollary 2: Consider two regions with cross-border pollution. Each region uses interregionally tradable emission permits and public pollution abatement. Capital can be internationally or only inter-regionally mobile. If $\theta=\theta^{*}=1$, then the non-cooperative and cooperative equilibrium level of emission permits are identical and equally efficient.

Ogawa and Wildasin (2009) show that when pollution is related to the use of capital, decentralized policymaking, i.e., the non-cooperative choice of the capital tax by each region, is efficient when the net rate of return to capital is fixed. Here, when pollution is a by-product of production, and regions use inter-regionally tradable emission permits and public pollution abatement, then, regardless of whether the rate of return to capital is fixed (ICM) or endogenous (RCM), decentralized policymaking is efficient in the case of perfect crossborder pollution. Moreover, as stated in the Introduction, a crucial feature of our model, in contrast to the (OW) and (ER) analytical frameworks, is the pivotal role of public pollution abatement. Specifically, removing lump-sum taxes and public good provision does not alter the results, in the sense that in (OW) decentralized policymaking remains efficient, while in (ER) remains inefficient. Here removing public pollution abatement, the decentralized 
environmental policy of either type, i.e., intra / inter-regionally tradable emission permits, always leads to a socially inefficient outcome.

\section{Concluding Remarks}

We build a model with two regions. The production in each region creates pollution which affects negatively consumers in both regions. To control pollution each region uses public pollution abatement and issues emission permits. We consider two cases, the case where emission permits are only intra-regionally tradable and the case where they are interregionally tradable. We examine the Nash and cooperative equilibrium levels of emission permits for these two cases when capital is internationally or only inter-regionally mobile.

Since most of the results are summarized in the various propositions, here we provide some general conclusions. Consider first the case where each region issues inter-regionally tradable emission permits: (i) if there is perfect cross border pollution between the two regions then the centralized (cooperative) and decentralized (non-cooperative) equilibrium level of emission permits are identical and equally efficient, (ii) if the rate of cross-border pollution is less than one, then the decentralized equilibrium level of emission permits is higher than the one of the centralized equilibrium, (iii) the difference between centralized and decentralized levels of emission permits increases as the rate of cross-border pollution decreases. These results hold irrespectively of the level of public pollution abatement and the regime of capital mobility, i.e., ICM or RCM.

Next, we examined the case where each region issues only intra-regionally tradable emission permits and there is ICM: (i) in the absence of cross-border pollution the centralized and decentralized equilibrium levels of emission permits are identical and equally efficient regardless of the level of public pollution abatement, (ii) when cross-border pollution exists, then the decentralized equilibrium level of emission permits is higher than the one of the centralized equilibrium, (iii) the difference between decentralized and centralized equilibrium levels of emission permits increases with higher rates of cross-border pollution. When regions are symmetric and there is RCM, then results (i) and (iii) also hold, while the level of decentralized equilibrium emission permits can either be higher or lower to that of the centralized equilibrium.

Based on results (i) of the previous two paragraphs, we can argue that when the rates of cross-border pollution are the same, then there is a critical rate relative to which if the common rate of cross-border pollution between the two regions is smaller (larger), it is less 
inefficient, and thus preferable, for both regions to issue intra-regionally (inter-regionally) tradable emission permits.

Finally note that many of the results of the paper hold even if public pollution abatement is not optimally provided. That is, they hold even if lump-sum taxes are zero and the government uses only the revenue from the sales of tradable emission permits to finance the provision of public pollution abatement.

\section{References}

Antoniou, F., P. Hatzipanayotou and P. Koundouri, 2014, Tradable permits vs. ecological dumping when governments act non-cooperatively, Oxford Economics Papers 66, 188208.

Beghin, J., D. Roland-Holst, and D. van der Mensbrugghe, 1997, Trade and pollution linkages: piecemeal reform and optimal intervention, Canadian Journal of Economics $30,442-455$.

Copeland, B., 1994, International trade and the environment: Policy reform in a polluted small open economy, Journal of Environmental Economics and Management 26, 4465.

Copeland, B., 2011, Trade and the Environment, in "Palgrave Handbook of International Trade" (D. Bernhofen, R. Falvey, D. Greenaway and U. Kreickemeir, Eds.), chapter 15, McMillan, London.

Copeland, B. and M.S. Taylor, 1995, Trade and transboundary pollution, American Economic Review 85, 716-737.

Copeland, B. and M.S. Taylor, 2005, Free trade and global warming: a trade theory view of the Kyoto protocol, Journal of Environmental Economics and Management 49, 205234.

Eichner, T. and M. Runkel, 2012, Interjurisdictional spillovers, decentralized policymaking, and the elasticity of capital supply, American Economic Review 102, 2349-2357.

Ellerman, D. and P. L. Joskow, 2008, The European Union's emissions trading system in perspective, Policy, Pew Center on Global Climate Change, Washington, D.C.

Fell, H. and D.T. Kaffine, 2014, Can decentralized planning really achieve first-best in the presence of environmental spillovers? Journal of Environmental Economics and Management 68, 46-53.

Hadjiyiannis, C., Hatzipanayotou, P., and M. S. Michael, 2009, Public pollution abatement, regional capital mobility, and tax competition, Southern Economic Journal 75, 703719.

Helm, C., 2003, International emissions trading with endogenous allowance choices, Journal of Public Economics 87, 2737-2747. 
Keen, M. and C. Kotsogiannis, 2014, Coordinating Climate and Trade Policies: Pareto Efficiency and the Role of Border Tax Adjustments, Journal of International Economics 91, 119-128.

Kotsogiannis, C. and A. Woodland, 2013, Climate and international trade policies when emissions affect production possibilities, Journal of Environmental Economics and Management 66, 166-184.

Linster, M. and F. Zegel, 2007, Pollution abatement and control expenditure in OECD countries, Discussion Paper. ENV/EPOC/SE (March 2007) 1. Paris: OECD.

Neary, P., 2006, International trade and the environment: Theoretical and policy linkages, Environmental and Resource Economics 33, 95-118.

Ogawa, H. and D. Wildasin, 2009, Think locally, act locally: Spillovers, spillbacks and efficient decentralized policy making, American Economic Review 99, 1206-1217.

Oates, W. and R. Schwab, 1988, Economic competition among jurisdictions: Efficiency enhancing or distortion inducing? Journal of Public Economics 35, 333-354.

Petchey, J., 2014, Environmental standards in a large open economy, Journal of Public Economic Theory, forthcoming.

Vlassis, N., 2013, The welfare consequences of pollution-tax harmonization, Environmental and Resource Economics 56, 227-238.

\section{Appendix: Comparative Statics Results}

\section{Appendix to Section 3}

Intra-regionally tradable emissions permits.

Equations (2), (3) and (8) produce a system of six equations in $\left(s_{n}, s_{n}^{*}, K, K^{*}, g, g^{*}\right)$.

Differentiating this system with respect to the policy variables $Z_{n}$ and $Z_{n}^{*}$ gives:

$$
\left[\begin{array}{cccccc}
R_{K K} & 0 & R_{K s_{n}} & 0 & 0 & 0 \\
0 & R_{K^{*} K^{*}}^{*} & 0 & R_{K^{*} s_{n}^{*}}^{*} & 0 & 0 \\
R_{K s_{n}} & 0 & R_{s_{n} s_{n}} & 0 & 0 & 0 \\
0 & R_{s_{n}^{*} K^{*}}^{*} & 0 & R_{s_{n}^{*} s_{n}^{*}}^{*} & 0 & 0 \\
0 & 0 & -Z_{n} & 0 & P_{g} & 0 \\
0 & 0 & 0 & -Z_{n}^{*} & 0 & P_{g}
\end{array}\right]\left[\begin{array}{c}
d K \\
d K^{*} \\
d s_{n} \\
d s_{n}^{*} \\
d g \\
d g^{*}
\end{array}\right]=\left[\begin{array}{c}
0 \\
0 \\
-1 \\
0 \\
s_{n} \\
0
\end{array}\right] d Z+\left[\begin{array}{c}
0 \\
0 \\
0 \\
-1 \\
0 \\
s_{n}^{*}
\end{array}\right] d Z^{*}
$$

from which we obtain the following results: 


$$
\begin{aligned}
& \frac{d s_{n}}{d Z_{n}}=-\tilde{R}_{s_{n} s_{n}}^{-1}<0, \frac{d K}{d Z_{n}}=\left(R_{K K} \tilde{R}_{s_{n} s_{n}}\right)^{-1} R_{K s_{n}}, \frac{d g}{d Z_{n}}=P_{g}^{-1}\left(s_{n}-\tilde{R}_{s_{n} s_{n}}^{-1} Z_{n}\right) . \\
& \frac{d s_{n}^{*}}{d Z_{n}}=\frac{d K^{*}}{d Z_{n}}=\frac{d g^{*}}{d Z_{n}}=0 .
\end{aligned}
$$

Differentiating $r=Z_{n}-g+\theta Z_{n}^{*}-\theta g^{*}$ and $r^{*}=Z_{n}^{*}-g^{*}+\theta^{*} Z_{n}-\theta^{*} g$ with respect to $Z_{n}$, and using equations (A.2) we obtain:

$$
\frac{d r}{d Z_{n}}=1-\frac{d g}{d Z_{n}}=P_{g}^{-1}\left(P_{g}-s_{n}+\tilde{R}_{s_{n} s_{n}}^{-1} Z_{n}\right), \quad \frac{d r^{*}}{d Z_{n}}=\theta^{*}-\theta^{*} \frac{d g}{d Z_{n}}=\theta^{*} P_{g}^{-1}\left(P_{g}-s_{n}+\tilde{R}_{s_{n} s_{n}}^{-1} Z_{n}\right) .
$$

Differentiating equations (4), (5) and using equations (A.2)-(A.3) yields the welfare effects of changes in $Z_{n}$ and $Z_{n}^{*}$, as given in equations (9)-(11) in the text.

Inter-regionally tradable emissions permits.

Equations (2), (3) and (12) produce a system of five equations in $\left(K, K^{*}, g, g^{*}, s_{t}\right)$. Differentiating this system with respect to the policy variables $Z_{t}$ and $Z_{t}^{*}$ gives:

$$
\left[\begin{array}{ccccc}
R_{K K} & 0 & R_{K s_{t}} & 0 & 0 \\
0 & R_{K^{*} K^{*}}^{*} & R_{K^{*} s_{t}}^{*} & 0 & 0 \\
R_{K s_{t}} & R_{K^{*} s_{t}}^{*} & H_{s_{t} s_{t}} & 0 & 0 \\
0 & 0 & -Z_{t} & P_{g} & 0 \\
0 & 0 & -Z_{t}^{*} & 0 & P_{g}
\end{array}\right]\left[\begin{array}{c}
d K \\
d K^{*} \\
d s_{t} \\
d g \\
d g^{*}
\end{array}\right]=\left[\begin{array}{c}
0 \\
0 \\
-1 \\
s_{t} \\
0
\end{array}\right] d Z_{t}+\left[\begin{array}{c}
0 \\
0 \\
-1 \\
0 \\
s_{t}
\end{array}\right] d Z_{t}^{*}
$$

from which we obtain the following results:

$$
\begin{aligned}
& \frac{d K}{d Z_{t}}=\frac{d K}{d Z_{t}^{*}}=\left(R_{K K} \tilde{H}_{s_{t} s_{t}}\right)^{-1} R_{K s_{t}}, \quad \frac{d K^{*}}{d Z_{t}}=\frac{d K^{*}}{d Z_{t}^{*}}=\left(R_{K^{*} K^{*}}^{*} \tilde{H}_{s_{t} s_{t}}\right)^{-1} R_{K^{*} s_{t}}^{*}, \\
& \frac{d g}{d Z_{t}}=P_{g}^{-1}\left(s_{t}+Z_{t} \frac{d s_{t}}{d Z_{t}}\right)=P_{g}^{-1}\left(s_{t}-\tilde{H}_{s_{t} s_{t}}^{-1} Z_{t}\right), \quad \frac{d g}{d Z_{t}^{*}}=P_{g}^{-1} Z_{t} \frac{d s_{t}}{d Z_{t}^{*}}=-\left(P_{g} \tilde{H}_{s_{t} s_{t}}\right)^{-1} Z_{t}, \\
& \frac{d g^{*}}{d Z_{t}^{*}}=P_{g}^{-1}\left(s_{t}+Z_{t}^{*} \frac{d s_{t}}{d Z_{t}^{*}}\right)=P_{g}^{-1}\left(s_{t}-\tilde{H}_{s_{t} s_{t}}^{-1} Z_{t}^{*}\right), \frac{d g^{*}}{d Z_{t}}=P_{g}^{-1} Z_{t}^{*} \frac{d s_{t}}{d Z_{t}}=-\left(P_{g} \tilde{H}_{s_{t} s_{t}}\right)^{-1} Z_{t}^{*}<0, \\
& \frac{d s_{t}}{d Z_{t}}=\frac{d s_{t}}{d Z_{t}^{*}}=-\tilde{H}_{s_{t} s_{t}}^{-1}<0,
\end{aligned}
$$

where $\tilde{H}_{s_{t} s_{t}}=H_{s_{t} s_{t}}-R_{s_{t} K^{*}}^{*} R_{K^{*} K^{*}}^{*-1} R_{K^{*} s_{t}}^{*}-R_{s_{t} K} R_{K K}^{-1} R_{K s_{t}}=\tilde{R}_{s_{t} s_{t}}+\tilde{R}_{s_{t} s_{t}}^{*}>0$ and $H_{s_{t} s_{t}}=R_{s_{t} s_{t}}+R_{s_{t} s_{t}}^{*}>0$. 
Differentiating

$$
r=-R_{s_{t}}\left(s_{t}, K\right)-g-\theta\left(R_{s_{t}}^{*}\left(s_{t}, K^{*}\right)+g^{*}\right),
$$

and

$r^{*}=-R_{s_{t}}^{*}\left(s_{t}, K^{*}\right)-g^{*}-\theta^{*}\left(R_{s_{t}}\left(s_{t}, K\right)+g\right)$, with respect to $Z_{t}$ and $Z_{t}^{*}$, and using equations (A.5) we get:

$$
\begin{aligned}
& \tilde{H}_{s_{t} s_{t}} \frac{d r}{d Z_{t}}=P_{g}^{-1}\left(-s_{t} \tilde{H}_{s_{t} s_{t}}+Z_{t}+\theta Z_{t}^{*}\right)+\tilde{R}_{s_{t} s_{t}}+\theta \tilde{R}_{s_{t} s_{t}}^{*}, \\
& \tilde{H}_{s_{t} s_{t}} \frac{d r}{d Z_{t}^{*}}=P_{g}^{-1}\left(-\theta s_{t} \tilde{H}_{s_{t} s_{t}}+Z_{t}+\theta Z_{t}^{*}\right)+\tilde{R}_{s_{t} s_{t}}+\theta \tilde{R}_{s_{t} s_{t}}^{*}=\frac{d r}{d Z_{t}}+P_{g}^{-1}(1-\theta) s_{t} \tilde{H}_{s_{t} s_{t}}^{2}, \\
& \tilde{H}_{s_{t} s_{t}} \frac{d r^{*}}{d Z_{t}^{*}}=P_{g}^{-1}\left(-s_{t} \tilde{H}_{s_{t} s_{t}}+Z_{t}^{*}+\theta^{*} Z_{t}\right)+\tilde{R}_{s_{t} s_{t}}^{*}+\theta^{*} \tilde{R}_{s_{t} s_{t}}, \\
& \tilde{H}_{s_{t} s_{t}} \frac{d r^{*}}{d Z_{t}}=P_{g}^{-1}\left(-\theta^{*} s_{t} \tilde{H}_{s_{t} s_{t}}+\theta^{*} Z_{t}+Z_{t}^{*}\right)+\tilde{R}_{s_{t} s_{t}}^{*}+\theta^{*} \tilde{R}_{s_{t} s_{t}}=\frac{d r^{*}}{d Z_{t}^{*}}+P_{g}^{-1}\left(1-\theta^{*}\right) s_{t} \tilde{H}_{s_{t} s_{t}}^{2} .
\end{aligned}
$$

The welfare effects of changes in $Z_{t}$ and $Z_{t}^{*}$ are obtained as follows. Differentiating equations (1)-(5) and (12) with respect to $Z_{t}$ and $Z_{t}^{*}$, and using equations (A.5) and (A.6), yields equations (13) and (14) in the text, and the following:

$$
\begin{gathered}
P_{g} \tilde{H}_{s_{t} s_{t}} E_{u^{*}}^{*} \frac{d u^{*}}{d Z_{t}}=E_{r^{*}}^{*}\left(-z+Z_{t}\right)+E_{r^{*}}^{*} \tilde{H}_{s_{t} s_{t}}\left(\theta^{*} s_{t}-P_{g}\right)+R_{s_{t}}^{*}\left(E_{r^{*}}^{*}-P_{g}\right)+E_{r^{*}}^{*}\left[-\theta^{*} Z_{t}+\left(1-\theta^{*}\right) P_{g} \tilde{R}_{s_{t} s_{t}}\right] \\
P_{g} \tilde{H}_{s_{t} s_{t}} E_{u} \frac{d u}{d Z_{t}^{*}}=E_{r}\left(-z^{*}+Z_{t}^{*}\right)+E_{r} \tilde{H}_{s_{t} s_{t}}\left(\theta s_{t}-P_{g}\right)+R_{s_{t}}\left(E_{r}-P_{g}\right)+E_{r}\left[-\theta Z_{t}^{*}+(1-\theta) P_{g} \tilde{R}_{s_{t} s_{t}}^{*}\right]
\end{gathered}
$$

Adding and subtracting the expression $s_{t} \tilde{H}_{s_{t} s_{t}} E_{r^{*}}^{*}$ in the right-hand-side of equation (A.7) produces equation (15) in the text.

\section{Appendix to Section 4}

Intra-regionally tradable emissions permits.

Equations (2), (8) and (16) constitute a system of five equations in $\left(K, g, g^{*}, s_{n}, s_{n}^{*}\right)$. Differentiating it with respect to $Z_{n}$ and $Z_{n}^{*}$ we obtain:

$$
\left[\begin{array}{ccccc}
H_{K K} & R_{K s_{n}} & R_{K s_{n}^{*}}^{*} & 0 & 0 \\
R_{s_{n} K} & R_{s_{n} s_{n}} & 0 & 0 & 0 \\
-R_{s_{n}^{*} K}^{*} & 0 & R_{s_{n}^{*} s_{n}^{*}}^{*} & 0 & 0 \\
0 & -Z_{n} & 0 & P_{g} & 0 \\
0 & 0 & -Z_{n}^{*} & 0 & P_{g}
\end{array}\right]\left[\begin{array}{c}
d K \\
d s_{n} \\
d s_{n}^{*} \\
d g \\
d g^{*}
\end{array}\right]=\left[\begin{array}{c}
0 \\
-1 \\
0 \\
s_{n} \\
0
\end{array}\right] d Z_{n}+\left[\begin{array}{c}
0 \\
0 \\
-1 \\
0 \\
s_{n}^{*}
\end{array}\right] d Z_{n}^{*}
$$

from which we get: 


$$
\begin{gathered}
\frac{d K}{d Z_{n}}=\Delta_{n}^{-1} R_{K s_{n}} R_{s_{n}^{*} s_{n}^{*}}^{*}>0, \frac{d s_{n}}{d Z_{n}}=-\Delta_{n}^{-1} R_{s_{n}^{*} s_{n}^{*}}^{*}\left(R_{K K}+\tilde{R}_{K^{*} K^{*}}^{*}\right)<0, \frac{d s_{n}^{*}}{d Z_{n}}=\Delta_{n}^{-1} R_{K s_{n}} R_{K^{*} s_{n}^{*}}^{*}<0 \\
\frac{d g}{d Z_{n}}=P_{g}^{-1} \Delta_{n}^{-1}\left\{-Z_{n}\left(H_{K K} R_{s_{n}^{*} s_{n}^{*}}^{*}-R_{s_{n}^{*} K^{*}}^{*} R_{K^{*} s_{n}^{*}}^{*}\right)+s_{n}\left[-R_{K^{*} s_{n}^{*}}^{*} R_{s_{n}^{*} K^{*}}^{*} R_{s_{n} s_{n}}+R_{s_{n}^{*} s_{n}^{*}}^{*}\left(H_{K K} R_{s_{n} s_{n}}-R_{K s_{n}} R_{s_{n} K}\right)\right]\right\} \Rightarrow \\
\Rightarrow \frac{d g}{d Z_{n}}=P_{g}^{-1}\left(Z_{n} \frac{d s_{n}}{d Z_{n}}+s_{n}\right), \\
\frac{d g^{*}}{d Z_{n}}=\left(P_{g} \Delta_{n}\right)^{-1} Z_{n}^{*} R_{K s_{n}} R_{K^{*} s_{n}^{*}}^{*}=P_{g}^{-1} Z_{n}^{*} \frac{d s_{n}^{*}}{d Z_{n}}
\end{gathered}
$$

Differentiating $r=Z_{n}-g+\theta Z_{n}^{*}-\theta g^{*}$ and $r^{*}=Z_{n}^{*}-g^{*}+\theta^{*} Z_{n}-\theta^{*} g$ with respect to $Z_{n}$, and using the above results, we obtain:

$$
\begin{aligned}
& \frac{d r}{d Z_{n}}=1-\frac{d g}{d Z_{n}}-\theta \frac{d g^{*}}{d Z_{n}}=\left(P_{g} \Delta_{n}\right)^{-1}\left(\Delta_{n}\left(P_{g}-s_{n}\right)+Z_{n} R_{s_{n} s_{n}^{*}}^{*}\left(R_{K K}+\tilde{R}_{K^{*} K^{*}}^{*}\right)-\theta Z_{n}^{*} R_{K s_{n}} R_{s_{n}^{*} K^{*}}^{*}\right), \\
& \frac{d r^{*}}{d Z_{n}}=\theta^{*}-\frac{d g^{*}}{d Z_{n}}-\theta^{*} \frac{d g}{d Z_{n}}=\left(P_{g} \Delta_{n}\right)^{-1}\left(\Delta_{n} \theta^{*}\left(P_{g}-s_{n}\right)-Z_{n}^{*} R_{K s_{n}} R_{s_{n}^{*} K^{*}}^{*}+\theta^{*} Z_{n}\left(R_{K K}+\tilde{R}_{K^{*} K^{*}}^{*}\right)\right) .
\end{aligned}
$$

The welfare effects of changes in $Z_{t}$ and $Z_{t}^{*}$ are obtained as follows. Differentiating equation (17) with respect to $Z_{n}$, using equations (A.11)-(A.12), we obtain:

$$
E_{u} \frac{d u}{d Z_{n}}=-E_{r} P_{g}^{-1}\left(P_{g}-s_{n}\right)+\left[P_{g}^{-1} Z_{n}\left(E_{r}-P_{g}\right)-k R_{K s_{n}}\right] \frac{d s_{n}}{d Z_{n}}+E_{r} \theta P_{g}^{-1} Z_{n} \frac{d s_{n}^{*}}{d Z_{n}}-k R_{K K} \frac{d K}{d Z_{n}} .
$$

Substituting equations (A.10)-(A.12) in (A.13) yields equation (19) in the text. Similarly, to obtain $\left(d u^{*} / d Z_{n}^{*}\right)$, we differentiate equation (18) with respect to $Z_{n}^{*}$, and following the previous steps yields equation (20) in the text. Furthermore we can obtain:

$$
\begin{gathered}
E_{u^{*}}^{*} \frac{d u^{*}}{d Z_{n}}=P_{g}^{-1} E_{r^{*}}^{*} \theta^{*}\left(s_{n}-P_{g}\right)+P_{g}^{-1} Z_{n}^{*}\left(E_{r^{*}}^{*}-P_{g}\right) \frac{d s_{n}^{*}}{d Z_{n}}+P_{g}^{-1}\left(E_{r^{*}}^{*} \theta^{*} Z_{n}+P_{g} k R_{K s_{n}}\right) \frac{d s_{n}}{d Z_{n}}+k R_{K K} \frac{d K}{d Z_{n}} \Rightarrow \\
\Delta_{n} P_{g} E_{u^{*}}^{*} \frac{d u^{*}}{d Z_{n}}=-\Delta_{n} \theta^{*} E_{r^{*}}^{*}\left(P_{g}-S_{n}\right)+Z_{n}^{*}\left(E_{r^{*}}^{*}-P_{g}\right) R_{K_{n}} R_{s_{n}^{*} K^{*}}^{*}-\theta^{*} E_{r^{*}}^{*} Z_{n} R_{s_{n}^{*} s_{n}^{*}}^{*}\left(R_{K K}+\tilde{R}_{K^{*} K^{*}}^{*}\right)-k P_{g} R_{K s_{n}} R_{s_{n}^{*} n_{n}^{*}}^{*} \tilde{R}_{K^{*} K^{*}}^{*} \cdot(\mathrm{A} .14)
\end{gathered}
$$

Assuming symmetric regions, so that $k=0$, and using the f.o.c. $d u / d Z_{n}=0$ in equation (A.14) yields equation (21) in the text. 
The effects of changes in $\theta$ and $\theta^{*}$ on $Z_{n}^{N}$ and $Z_{n}^{* N}$ emerge from total differentiation of the best-response functions $F_{Z_{n}}=0$ and $F_{Z_{n}^{*}}^{*}=0$, assuming that the third derivatives are zero. Doing so gives the following system of equations.

$$
\left[\begin{array}{cc}
F_{Z_{n} Z_{n}} & F_{Z_{n} Z_{n}^{*}} \\
F_{Z_{n}^{*} Z_{n}}^{*} & F_{Z_{n}^{*} Z_{n}^{*}}^{*}
\end{array}\right]\left[\begin{array}{l}
d Z_{n}^{N} \\
d Z_{n}^{* N}
\end{array}\right]=\left[\begin{array}{c}
-F_{Z_{n} \theta} \\
-F_{Z_{n}^{*} \theta}^{*}
\end{array}\right] d \theta+\left[\begin{array}{c}
-F_{Z_{n} \theta^{*}} \\
-F_{Z_{n}^{*} \theta^{*}}^{*}
\end{array}\right] d \theta^{*} .
$$

where $\Omega=R_{s_{n} s_{n}} R_{s_{n}^{* s_{n}}}^{*}\left(R_{K K}+\tilde{R}_{K^{*} K^{*}}^{*}\right)\left(R_{K^{*} K^{*}}^{*}+\tilde{R}_{K K}\right)-(1+\theta)\left(1+\theta^{*}\right)\left(R_{K s_{n}} R_{s_{n}^{*} K^{*}}^{*}\right)^{2}$ is the determinant of the left-hand-side coefficients matrix and is positive for stability. Also:

$$
\begin{aligned}
& F_{Z_{n} Z_{n}}=R_{s_{n}^{*} s_{n}^{*}}^{*}\left(R_{K K}+\tilde{R}_{K^{*} K^{*}}^{*}\right)<0, F_{Z_{n}^{*} Z_{n}^{*}}^{*}=R_{s_{n} s_{n}}\left(R_{K^{*} K^{*}}^{*}+\tilde{R}_{K K}\right)<0, F_{Z_{n} \theta}=-Z^{*} R_{K s_{n}} R_{s_{n}^{*} K^{*}}^{*}<0, \\
& F_{Z_{n} Z_{n}^{*}}=-(1+\theta) R_{K s_{n}} R_{s_{n}^{*} K^{*}}^{*}<0, F_{Z_{n}^{*} Z_{n}}^{*}=-\left(1+\theta^{*}\right) R_{K s_{n}} R_{s_{n}^{*} K^{*}}^{*}<0, F_{Z_{n}^{*} \theta^{*}}^{*}=-Z R_{K s_{n}} R_{s_{n}^{*} K^{*}}^{*}<0, \\
& F_{Z_{n} \theta^{*}}=F_{Z_{n}^{*} \theta}^{*}=0 .
\end{aligned}
$$

The two best-response functions are negatively slopped, i.e., $\left.\left(d Z_{n}^{N} / d Z_{n}^{* N}\right)\right|_{F_{Z_{n}}=0}=-F_{Z_{n} Z_{n}}^{-1} F_{Z_{n} Z_{n}^{*}}<0$ and $\left.\left(d Z_{n}^{N} / d Z_{n}^{* N}\right)\right|_{F_{Z_{n}^{*}}^{*}=0}=-F_{Z_{n}^{*} Z_{n}}^{*_{-1}} F_{Z_{n}^{*} Z_{n}^{*}}^{*}<0$. Then, we obtain:

$$
\Omega \frac{d Z_{n}^{N}}{d \theta}=-F_{Z_{n} \theta} F_{Z_{n}^{*} Z_{n}^{*}}^{*}<0, \quad \Omega \frac{d Z_{n}^{* N}}{d \theta}=F_{Z_{n}^{*} Z_{n}}^{*} F_{Z_{n} \theta}>0
$$

Inter-regionally tradable emissions permits.

From equations (2), (12) and (16) we have a system of four equations in $K, s_{t}, g$ and $g^{*}$ in terms of $Z_{t}$ and $Z_{t}^{*}$. Differentiating this system with respect to $Z_{t}$ we get the following results:

$$
\left[\begin{array}{cccc}
H_{K K} & H_{K s_{t}} & 0 & 0 \\
H_{s_{t} K} & H_{s_{t} s_{t}} & 0 & 0 \\
0 & -Z_{t} & P_{g} & 0 \\
0 & -Z_{t}^{*} & 0 & P_{g}
\end{array}\right]\left[\begin{array}{c}
d K \\
d s_{t} \\
d g \\
d g^{*}
\end{array}\right]=\left[\begin{array}{c}
0 \\
-1 \\
s_{t} \\
0
\end{array}\right] d Z_{t}+\left[\begin{array}{c}
0 \\
-1 \\
0 \\
s_{t}
\end{array}\right] d Z_{t}^{*},
$$

from which we obtain: $\frac{d K}{d Z_{t}}\left(=-\frac{d K^{*}}{d Z_{t}}\right)=\Delta_{t}^{-1} H_{K s_{t}}, \frac{d s_{t}}{d Z_{t}}=-\Delta_{t}^{-1} H_{K K}=-\bar{H}_{s_{t} s_{t}}^{-1}<0$,

$$
\frac{d g}{d Z_{t}}=\left(P_{g} \Delta_{t}\right)^{-1} H_{K K}\left(-Z_{t}+s_{t} \bar{H}_{s_{t} s_{t}}\right) \Rightarrow \frac{d g}{d Z_{t}}=P_{g}^{-1}\left(Z_{t} \frac{d s_{t}}{d Z_{t}}+s_{t}\right),
$$

where, $\Delta_{t}=H_{K K} \bar{H}_{s_{t} s_{t}}<0$. 
Differentiating

$$
r=-R_{s_{t}}\left(s_{t}, K\right)-g-\theta\left(R_{s_{t}}^{*}\left(s_{t}, K^{*}\right)+g^{*}\right)
$$

and

$r^{*}=-R_{s_{t}}^{*}\left(s_{t}, K^{*}\right)-g^{*}-\theta^{*}\left(R_{s_{t}}\left(s_{t}, K\right)+g\right)$ with respect to $Z_{t}$ we get:

$$
\begin{aligned}
& \frac{d r}{d Z_{t}}=-P_{g}^{-1} s_{t}-\left[\left(Z_{t}+\theta Z_{t}^{*}\right) P_{g}^{-1}+\left(R_{s_{t} s_{t}}+\theta R_{s_{t} s_{t}}^{*}\right)\right] \frac{d s_{t}}{d Z_{t}}-\left(R_{s_{t} K}-\theta R_{s_{t} K^{*}}^{*}\right) \frac{d K}{d Z_{t}}, \\
& \frac{d r^{*}}{d Z_{t}}=-\theta^{*} P_{g}^{-1} s_{t}-\left[\left(Z_{t}^{*}+\theta^{*} Z_{t}\right) P_{g}^{-1}+\left(R_{s_{t} s_{t}}^{*}+\theta^{*} R_{s_{t} s_{t}}\right)\right] \frac{d s_{t}}{d Z_{t}}-\left(\theta^{*} R_{s_{t} K}-R_{s_{t} K^{*}}^{*}\right) \frac{d K}{d Z_{t}} .
\end{aligned}
$$

To obtain the effect of changes in $Z_{t}$ on $u^{*}$, we differentiate equations (1), (2), (12), (16) and (18) with respect to $Z_{t}$, and use equations (A.17)-(A.19). Thus, we get:

$$
\begin{aligned}
& P_{g} \bar{H}_{s_{t} s_{t}} E_{u^{*}}^{*} \frac{d u^{*}}{d Z_{t}}=E_{r^{*}}^{*} \bar{H}_{s_{t} s_{t}}\left(\theta^{*} s_{t}-P_{g}\right)+R_{s_{t}}^{*}\left(E_{r^{*}}^{*}-P_{g}\right)+ \\
& E_{r^{*}}^{*}\left[R_{s_{t}}+\left(1-\theta^{*}\right)\left(Z_{n}+P_{g} R_{s_{t} s_{t}}-P_{g} R_{s_{t} \mathrm{~K}} H_{K K}^{-1} H_{K s_{t}}\right)\right]-k P_{g} H_{K K}^{-1}\left(R_{K K} R_{K^{*} s_{t}}^{*}+R_{K s_{t}} R_{K^{*} K^{*}}^{*}\right)
\end{aligned}
$$

In equation (A.20) adding and subtracting some terms yields equation (24). 